\title{
Statistical points and pitfalls
}

\author{
Jimmie Leppink ${ }^{1} \cdot$ Patricia O'Sullivan $^{2} \cdot$ Kal Winston $^{3}$
}

Published online: 14 January 2016

(C) The Author(s) 2016. This article is published with open access at Springerlink.com

Many readers of this journal are involved in teaching or designing educational programmes or studies. Often, either by yourself or in conjunction with others, you need to design studies asking questions such as what is the best approach for teaching this material for a particular type of learner? What context makes a difference in learner performance? What strategies motivate learners better than others? In planning these studies, there are many design considerations necessary to ensure that the results are meaningful. During the planning of the studies, and subsequently, numerous questions arise concerning the use of statistics. We recognize that medical educational researchers are often not particularly comfortable with statistics and thus could easily slip into making poor decisions about what to do with quantitative data in the study.

Even if your study is designed carefully, choices made inherently lead to a study that has both strengths and limitations. You are now faced with the question of how to present the outcomes of your study and how to formulate implications for educational practice and future research. In this process, you have a diverse toolbox at your disposal from which you need to select tools to match your study, the research questions, and the nature of the data collected. In some types of studies, we tend to make inappropriate data choices [1] either because we are not aware of better alternatives or of how much difference these alternatives can

Jimmie Leppink

jimmie.leppink@maastrichtuniversity.nl

Maastricht University, Maastricht, The Netherlands

University of California, San Francisco, USA

University of Liverpool Online, Amsterdam, The Netherlands make for the interpretations of findings and the implications thereof for educational practice and future research.

A new section of Perspectives on Medical Education, entitled Statistical points and pitfalls, directly tackles these analytical issues. The overall purpose of this series is to help readers and researchers alike increase awareness of how to use statistics, why and how we fall into inappropriate choices or interpretations, and what we can do about it. We hope to help readers understand common misconceptions and give clear guidance on how to avoid common pitfalls by offering simple tips to improve the reporting of quantitative research findings. Each entry discusses a commonly encountered inappropriate practice and offers alternatives from a pragmatic perspective with no mathematics involved. This issue's inaugural edition of Statistical points and pitfalls addresses the question of when it is appropriate to do a statistical test. In it, we present the conditions that ought to be met for a statistical test to be used and what to do otherwise [2].

Whether you are an educator trying to select the most appropriate methods to deliver effective learning for your students, a researcher trying to improve your reporting of quantitative findings, or simply want to gain a critical understanding of the literature that you read, this section is for you. If you supervise others' research but you struggle to give concrete feedback on how to improve, you will also find useful assistance here. Suggestions for future editions of this section can be shared on Twitter, using the hashtag \#mededstats. We hope you find Statistical points and pitfalls accessible, instructive, and entertaining.

Open Access This article is distributed under the terms of the Creative Commons Attribution 4.0 International License (http://creativecommons. org/licenses/by/4.0/), which permits unrestricted use, distribution, and reproduction in any medium, provided you give appropriate credit to the original author(s) and the source, provide a link to the Creative Commons license, and indicate if changes were made. 


\section{References}

1. Leppink J, Kok EM, Bergman EM, Van Loon MH, De Bruin ABH. Four common pitfalls of quantitative analysis in experimental research. Acad Med. 2015. doi:10.1097/ACM.0000000000000946.

2. Leppink J, Winston K, O'Sullivan P. Statistical points and pitfalls: introduction. Perspect Med Educ. 2016;5. doi: 10.1007/ s40037-015-0247-z.

Dr. Jimmie Leppink is currently postdoctoral researcher, consultant for and teacher in quantitative methodology and analysis, and data manager for the School of Health Professions Education, Maastricht University, the Netherlands. His research focuses on adaptive approaches to learning and assessment, cognitive load theory and measurement, and multilevel analysis of educational data.
Dr. Patricia O'Sullivan has spent over 35 years in medical education. Much of her experience is with graduate medical education and the discussion of competency based education. She has also taught statistics at the graduate level for 10 years.

Dr. Kal Winston has spent over 30 years teaching language, mathematics, study skills and critical thinking at a range of levels, including over a decade in medical education. He currently teaches in the Doctorate of Education programme at University of Liverpool Online. 